\title{
LETTER
}

\section{Abundances of monoisotopic REE, consistent with the Leedey chondrite values}

\author{
(Received July 26, 1975)
}

Lately the number of papers dealing with REE geochemistry is rapidly increasing, and in most of them, the Masuda-Coryell plot (MASUdA, 1962; CoRYell et al., 1963) is employed, which rests on the abundance ratios between the sample studied and the chondrite. That is, the REE abundances in chondrites serve as normalizing values.

The relative abundances of REE in ordinary chondrites were considered to be constant (SchmitT et al., 1963, 1964), but the precise determinations (MASUdA et al., 1973; NAKAMURA, 1974) demonstrated that mutually normalized REE patterns even among the ordinary chondrites themselves have fine structures depending on the particular samples. MASUDA et al. (1973) advocated that the REE abundances in the Leedey chondrite analyzed by them be employed as reference values. NAKAmura (1974) proved that these Leedey values of REE abundances are about 1.13 times the corresponding ones for the average of ten "normal" ordinary chondrites, but there are little variations in relative abundances between two sets of values. (Specifically, NAKAMURA (1974) suggests that, in a relative sense, the $\mathrm{Ce}$ and $\mathrm{Yb}$ abundances in "Leedey" are 1.5 and $0.6 \%$ too low, respectively, when compared with his average values.)

Thus the REE abundances obtained for the Leedey sample are being employed instead of the ones previously presented for chondrites. However, the set of the Leedey REE abundances has a shortcoming that it is void of abundances for monoisotopic REE, i.e., $\mathrm{Pr}, \mathrm{Tb}$, Ho and $\mathrm{Tm}$, because the stable isotope dilution technique as employed by MASUDA et al. (1973) can be applied to determination of elements with two or more stable isotopes, not of those comprising single stable isotopes. The purpose of this communication is to fill the void abundances for the above four elements so that their abundances are consistent with those of polyisotopic REE obtained for Leedey.

There can be two ways of estimation of abundances in question. One of them (method A) is interpolation on a smooth abundance curve for odd-A nuclides (SuESS and UREY, 1956; SCHMITT et al., 1963); the accurate data on REE in Leedey will be used to secure a smooth curve for span of mass number from 139 through 175. Another one (method B) is estimation based on a linear curve for the chondrite-normalized REE pattern defined by other polyisotopic REE, mostly, with even-Z numbers. Also for the latter method, the Leedey abundances cited above will serve as a basis, i.e., as a set of normalizing values.

If position of a certain nuclide is unequivocally determined on a smooth odd-A nuclide abundance curve, employement of method $\mathrm{A}$ is advantageous in that the abundance to be obtained can be decided without invoking the abundance data by the neutron activation analysis, and, accordingly, free from the experimental errors possibly involved in the activation analysis.

Of the four elements under consideration, only $\mathrm{Tb}$ with mass number of $159 \mathrm{can}$ be definitely located on the odd-A curve, because the curve passing through ${ }^{157} \mathrm{Gd},{ }^{161} \mathrm{Dy}$ and

${ }^{163} \mathrm{Dy}$ is a monotonous one with a gentle slope. According to this smooth segment, ${ }^{159} \mathrm{~Tb}$ abundance consistent with the Leedey set is estimated to be $0.0589 \mathrm{ppm}$. To our regret, however, it is rather hard for us to estimate the abundances of other three elements in that way, because each of them occupies somewhat critical position. Therefore, let us estimate the abundances of $\mathrm{Pr}$, Ho and Tm by means of method B.

For the purpose of estimation mentioned above, the abundance data by the neutron activation analysis on the following five samples have been taken up: Kilauea Iki- 22 basalt, Roberts Victor mine eclogite, and average chondrite (Schmiтt et al., 1963), North American 
Table 1. Abundances (ppm) of monoisotopic REE estimated by method B (see text)

\begin{tabular}{lllllll}
\hline & $(1)$ & $(2)$ & $(3)$ & $(4)$ & \multicolumn{1}{c}{$(5)$} & \multicolumn{2}{c}{ Adopted } \\
\hline $\mathrm{Pr}$ & 0.130 & 0.176 & 0.143 & 0.146 & 0.129 & $0.136 \pm 0.006$ \\
$\mathrm{~Tb}$ & 0.0606 & 0.0581 & 0.0587 & 0.0680 & 0.0590 & $0.0589 * \pm 0.0002$ \\
$\mathrm{Ho}$ & 0.0821 & 0.0900 & 0.0925 & 0.0832 & 0.0875 & $0.0888 \pm 0.0012$ \\
$\mathrm{Tm}$ & 0.0375 & 0.0379 & 0.0400 & 0.0400 & 0.0375 & $0.0385 \pm 0.0010$ \\
\hline
\end{tabular}

(1): From Kilauea Iki-22 basalt (SCHMitT et al., 1963).

(2): From Roberts Victor mine eclogite (SCHMITT et al., 1963).

(3): From average chondrite (SCHMITT et al., 1963).

(4): From North American shales (HASKIN and HASKIN, 1966).

(5): From composite chondrite (FREY et al., 1968).

* Value obtained by method A (see text).

shales (HASKIN and HASKIN, 1966) and composite chondrite (FrEY et al., 1968). The results of the estimation are shown in Table 1.

As seen in Table 1, the Tb abundance obtained by method $\mathrm{A}$ is in good agreement with that by method B. The values presented in the farthest right column are those adopted as consistent with the Leedey REE abundances obtained by MASUDA et al. (1973). Of these four adopted values, it is obvious that the Pr abundance is open to a comparatively large uncertainty. Generally, the adopted values well document the data on composite chondrite (FREY et al., 1968).

Department of Earth Sciences,

Akimasa Masuda

Faculty of Science, Kobe University,

Rokkodai, Nada, Kobe 657, Japan

\section{REFERENCES}

Coryell, C. D., Chase, J. W. and W inchester, J. W. (1963) A procedure for geochemical interpretation of terrestrial rare-earth abundance patterns. J. Geophys. Res. 68, 559-566.

Frey, F. A., HASkin, M. A., PoETZ, J. A. and HASkin, L. A. (1968) Rare earth abundances in some basic rocks. J. Geophys. Res. 73, 6085-6098.

HASKIN, M. A. and HASKIN, L. A. (1966) Rare earths in European shales: A redetermination. Science 154, 507-509.

KolJonen, T. and RosenberG, R. J. (1974) Rare earth elements in granitic rocks. Lithos 7, 249-261.

MASUDA, A. (1962) Regularities in variation of relative abundances of lanthanide elements and an attempt to analyse separation-index patterns of some minerals. J. Earth Sci., Nagoya Univ. 10, $173-187$.

Masuda, A., NAKamura, N. and TANAKA, T. (1973) Fine structures of mutually normalized rareearth patterns of chondrites. Geochim. Cosmochim. Acta 37, 239-248.

NAKAMURA, N. (1974) Determination of REE, $\mathrm{Ba}, \mathrm{Fe}, \mathrm{Mg}, \mathrm{Na}$ and $\mathrm{K}$ in carbonaceous and ordinary chondrites. ibid. 38, 757-775.

Schmitt, R. A., Smith, R. H., LASCh, J. E., Mosen, A. W., Olehy, D. A. and Vasilevskis, J. (1963) Abundances of the fourteen rare-earth elements, scandium, and yttrium in meteoritic and terrestrial matter. ibid. 27, 577-622.

Schmitt, R. A., Smith, R. H. and Olehy, D. A. (1964) Rare-earth, yttrium and scandium abundances in meteoritic and terrestiral matter - II. ibid. 28, 67-86.

SuESS, H. E. and UREY, H. C. (1956) Abundances of the elements. Revs. Modern Phys. 28, 53-74.

Note added in proof: KOLJONEN and ROSENBERG (1974) have presented another similar set. 